\title{
Negation and Negative Polarity Items in Berber
}

\author{
HAMID OUALI \\ University of Michigan
}

\section{Introduction}

The main goals of this paper are: (a) to provide an analysis of sentential negation that captures the variation in the strategies used to express it across Berber dialects; (b) to provide evidence that the Negation head $u r$ (Neg1) is generated as a head of NegP higher than TP and that sha (Neg2) is adjoined to VP, therefore sha-ur is a derived order as opposed to French pas-ne which was argued to be a basic order; (c) to show that sha (Neg2) is licensed via Spec-Head only and so are higher NPI adverbs like never-NPI's like no one and nothing are licensed via c-command; and (d) to argue that NPI licensing is done under strict locality conditions.

This paper offers an analysis that captures the micro-variation in the strategies used to express negation across Berber dialects. I argue that the "optional" negation markers sha (Tamazight)/ ara (Taqbaylit)/ kra (Tarifit) should not be ignored in any syntactic analysis of Berber negation and show that they have serious implications concerning the structure of this language.

There are two types of dialects with regard to how negation is expressed. Type 1 uses one negation marker; these dialects are Tachelhit and Touareg (see section 1). Type 2 uses the negation markers Neg1 and Neg2 and there two subgroups within this type. In the first group, which includes Tarifit, Taqbaylit, and Chaoui, Neg1 is always pre-verbal and Neg2 is always post-verbal. In the second group, which consists only of one dialect, namely Tamazight, Neg1 behaves in the same way as in the other dialects but Neg2 behaves differently in the sense that it can either be post-verbal or pre-verbal. This is schematized in (1).

(1) Type 1: One Neg

Type 2: Two Negs: Type2a. (Neg1...Verb (Neg2))

Type2b. ((Neg2)-Neg1...Verb (Neg2))

Tamazight has two different strategies to express sentential negation. Sentential negation is expressed by means of a pre-verbal negative marker. 
(2) ur iddi wrba gher-skeela.

neg 3s.went boy to-school

'The kid didn't go to school.'

(3) ur iswi wmush lhlib.

neg 3s-drink cat milk

'The cat didn't drink milk.'

In this dialect sentential negation is also expressed by means of two negative markers.

(4) ur ughax sha lkthaab. neg1 1s-bought-1s neg2 book

'I did not buy the book.'

Taqbaylit, Chaoui, and Tarifit behave like Tamazight as illustrated in (5-7).

(5) ur kcimegh ara.

neg1 enter.past.1s neg2

'I didn't enter.'

(Taqbaylit)

Nait-Zerrad (1994:32)

(6) ud yusi-ca.

(Chaoui)

neg1 come.3sm-neg2

'He didn't come.'

Nait-Zerrad (1994:34)

(7) ur izri shi imams

neg1 see.past.3s neg2 mother-his

(Tarifit)

'He didn't see his mother'

The negation element $u r$ cannot occur post-verbally, as shown in (8) and (9).

(8) * thdda ur yemma gher souq.

(Tamazight) go.past.3sf neg mother-my to market

'My mother didn't go to the market.'

(9) *thdda shaur yemma gher souq. go.past.1sf neg2-neg1 mother-my to market

(Tamazight)

Let us look at each Negation element in turn. We will start with the pre-verbal negation, i.e., Neg, and how it is distributed across the Berber dialects and then look at the second negation, i.e., Neg2. 


\section{Hamid Ouali}

\section{First Negation Elements}

In all the Berber dialects the first negation element is obligatory and must be preverbal as shown in (10-13).

(10) ur th- lix (*ur) assa.

neg see.past.1s (*neg) day-this

(Tamazight)

'I haven't seen him today.'

(11) ur islim (*ur).

neg know.past.3s (*neg)

(Taqbaylit)

'He didn't know.'

(12) ur isha (*ur) imkli wehdu.

neg eat.past.3s (*neg) lunch alone

'He didn't have lunch alone.'

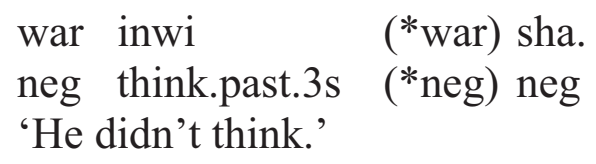

In each of these examples, putting Neg1 in a post-verbal position causes ungrammaticality. Let us see how Neg2 behaves across these dialects.

\section{Second Negation Elements}

When it comes to the second negation element, these dialects show some variation. In Touareg, as reported in Nait-Zerrad (1994), as well as in Tashelhit, it is nonexistent, as shown in (14) and (15). In Tamazight, Taqbaylit, and Tarifit, it is used optionally and has to appear after the verb, as shown in (16-18).

(14) ur tdda tfruxt s tgmmi. neg go-Perf-3sf to house

(Tashelhit)

'The girl did not go home.'

(15) wer tusa tabarart ehan. neg go-Perf-3sf to-house

(Touareg)

'The girl did not go home.'

(16) ur ssex (sha).

neg drink-Perf.1s (neg)

'I don't drink.'

(17) ur kshimegh (ara).

neg entered.past.1s (neg)

(Tashelhit)

(Tarifit)

'I didn't enter.' 
u-sn twshi (sha) arbii.

neg-them give.Past.3s (neg) grass

(Tarifit)

'She didn't give them grass.'

Unlike in Taqbaylit and Tarifit, in Tamazight the second negation element appears pre-verbally as shown in (19) below:
shaur dix gher-s.
neg-neg go.past.1s to-him
'I didn't go to him. / I didn't visit him.'

(Tamazight)

The distribution of Neg1 and Neg2 across Berber dialects is summarized in (20).

(20) Summary

$\begin{array}{lll}\begin{array}{ll}\text { Tashelhit/Touareg } \\ \text { ur...verb }\end{array} & \begin{array}{l}\text { Taqbaylit, Tarifit, Chaoui } \\ \text { ur...verb(sha) }\end{array} & \begin{array}{l}\text { Tamazight } \\ \text { ur...verb(sha) }\end{array} \\ & & \text { (sha) ur...verb(sha) }\end{array}$

\section{3. $\quad U r$ (Neg1) and Other Negative Polarity Items}

Ur (Neg1) co-occurs with NPI's like 'nothing' (21) and 'no one' (22). Walu 'nothing' in (21a), which is the direct object, appears after the verb and can also be topicalized and hence precede both $u r$ and the verb as in (21b). The same thing can be said about agidge 'no one', which is a pre-verbal subject in (22a) and topicalized in $(22 b)$.

$$
\begin{aligned}
& \text { a. ur as-wshi.x walu. } \\
& \text { neg him-give.Per.3s nothing } \\
& \text { 'I didn't give him anything.' } \\
& \text { b. walu ur-as-wshix. } \\
& \text { nothing Neg1-him-gave } \\
& \text { 'I gave him nothing.' }
\end{aligned}
$$
a. ur iddi agidge gher skuella.
neg go.Perf.3s no one school
'Nobody went to school.'
b. agidge ur iddin gher skuella. no one neg go.Perf.3s school 'Nobody went to school.'

I will argue below that these NPI's are licensed in their basic position via ccommand, a standard licensing configuration. This becomes clear when we look at their interaction with the second negation elements Neg2. Before we do that let us look at the negative adverbs. 
urgin 'never' type of NPI's can only occur in a position preceding both Neg1 and the verb as in (23).

$$
\begin{aligned}
& \text { urgin ur dix } \text { gher Frans. } \\
& \text { never neg go.Per.1s to France } \\
& \text { 'I've never been to France.' }
\end{aligned}
$$

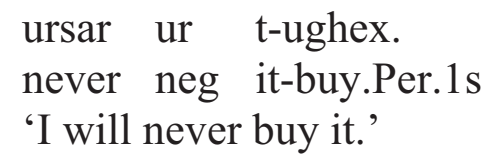

Examples (25) and (26) below show that the negative adverbs urdgin and usar cannot occur in a post-verbal position:

$$
\begin{aligned}
& \text { *ur dix urdgin gher frans. } \\
& \text { neg go.Perf.1s never to France } \\
& \text { 'I've never been to France. / I never went to France.' }
\end{aligned}
$$
(26) *ur t-ughex usar.
neg it-buy.Pef.1s never

'I will never buy it.'

Given these examples, I argue that these adverbs are not licensed via c-command but via Spec-Head relation with the negative head $u r$ by being externally merged in that position. I will come back to this point in detail in section 5 but first let us sketch the analysis I will use in this paper.

\section{Analysis}

I follow the standard assumption that Neg heads its own maximal projection, NegP. This assumption has been made for English and Romance (Pollock 1989, Chomsky 1989, Laka 1990, Zanuttini 1994) and for Berber (Ouhalla 1990, 1991; Ouali 1999, 2003).

a.

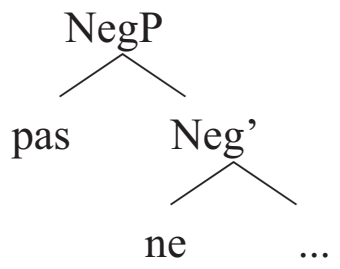

b.

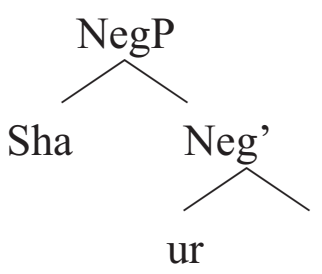

There are a number of arguments for Neg as head of NegP. First, it has been shown that Neg interacts with the verb by blocking V movement to $\mathrm{T}$ in English (Pollock 1989, Chomsky 1995). Second, it has been shown that Neg interacts with Tense and Agreement: Neg inflects for tense in Standard Arabic (Fassi-Fehri 1993) and for Agreement in Finnish. Third, it has been argued that Neg blocks 
clitic movement or the so-called clitic climbing in Italian (Kayne 1989), and in Berber Neg is one of the different head elements that can host object pronominal clitics (Ouhalla 1988; Ouali 1999, 2003a,b).

Pollock (1989) has proposed that French ne originates in a functional projection lower than Infl and then raises and adjoins to a higher functional head, whereas Laka (1990) and Zanuttini (1990, 1991), among others, have proposed that the pre-verbal negative markers of Italian and Spanish are the head of a functional projection higher than Infl. I will adopt the latter view and assume, following Ouhalla (1991), that Neg in Berber is higher than IP/TP. I will also assume that sha (Neg2) is adjoined to VP as illustrated in (28b) and later on moves to Spec-Neg, at LF presumably.
a. ur-da-dux
sha.
Neg1-Aux- go.1ps Neg2
'He will not go.'

b.

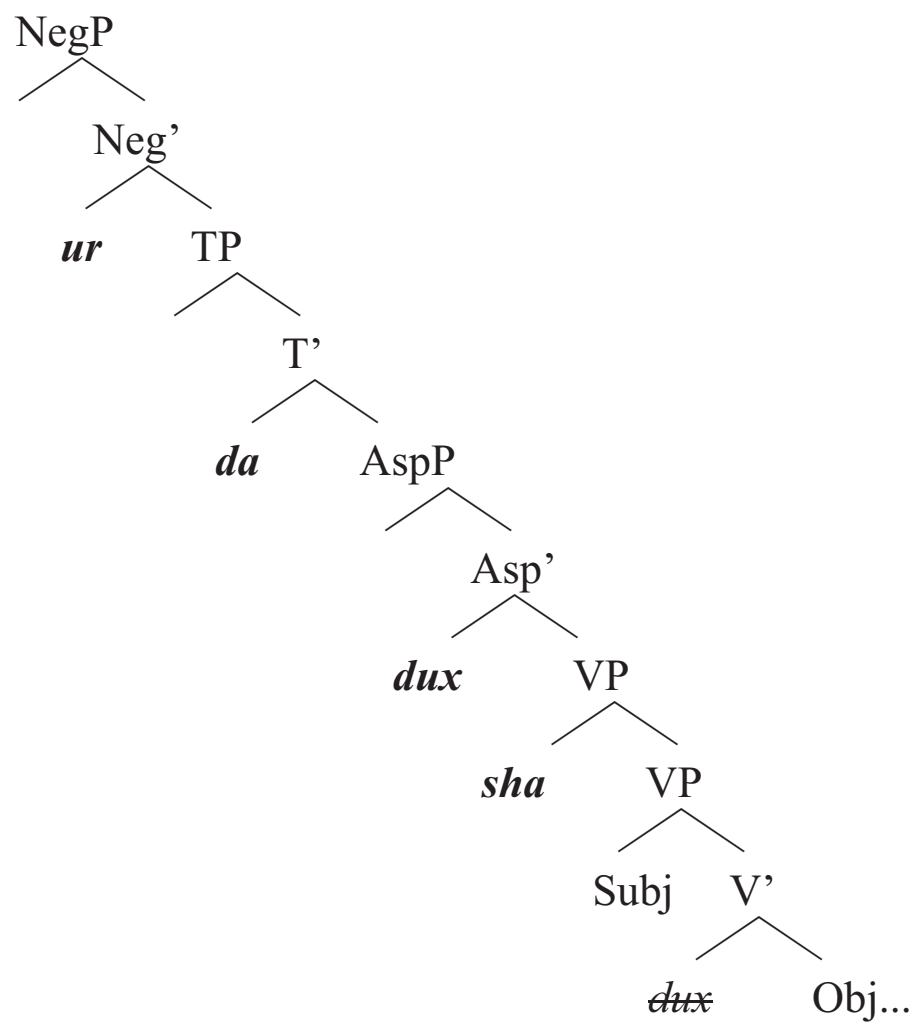

Given these assumptions, it follows that in Berber sha-ur (Neg2-Neg1) is a derived order, unlike in French where it is assumed that pas-ne (Neg2-Neg1) is the basic order (27a). This leads us to the following cross-linguistic comparison in (29), which basically shows that some Berber dialects, namely Touareg and Tashelhit, behave like some Romance languages, namely Italian, in having one Neg marker which is pre-verbal (29a). Others are like French in having two Neg markers and these are Tarifit, Taqbaylit, Chaoui, and Tamazight (29d). Also, it is 
known that in colloquial French ne (Neg1) can be dropped but pas (Neg2) cannot (29b). Tamazight is the mirror image of French, where sha (Neg2; the counterpart of pas) can be dropped whereas ur, the Neg head, cannot (29c). And finally Tamazight seems to be the only dialect where Neg2 can precede Neg1 (29e). The examples in (29a-c) are from Haegeman and Zanuttini (1996).

\section{Cross-linguistic comparison:}
a. Non mangia
Neg + finite $\mathrm{V}$
b. Il (ne) mange *(pas)
$(\mathrm{Neg})+$ finite $\mathrm{V}+*(\mathrm{Neg})$
Italian, Touareg, Tashelhit
c. A mengia nen
Finite $\mathrm{V}+\mathrm{Neg}$
French
d. ur la ytet (sha) 'He doesn't eat.'
$*(\mathrm{Neg} 1)+$ finite $\mathrm{V}+(\mathrm{Neg} 2)$
Piedmontese
e. sha ur la ytet
'He doesn't eat.'
$(\mathrm{Neg} 2)+*(\mathrm{Neg} 1)+$ finite $\mathrm{V}$ Tamazight

\section{Negative Polarity Items}

In section 2 I claimed that NPI's like agidge 'no one' in (30) are licensed in situ by virtue of being c-commanded by Neg. In (31) agidge is licensed prior to undergoing topicalization.

$$
\begin{array}{ll}
\text { ur iddi } & \text { agidge. } \\
\text { neg go-Perf-3s } & \text { no one } \\
\text { 'No one left.' } &
\end{array}
$$

agidge ur iddi-n.

no one neg go-Perf-NEU

'No one left.'

The evidence for agidge being topicalized comes from the agreement morphology on the verb. Any subject A'-extraction in Berber triggers what is called the AntiAgreement Effect, which is a neutral form of agreement (31) (see Ouhalla 1993). This shows that this NPI is not in Spec-Neg but presumably in Spec-CP. However, one might argue that it has moved through Spec-NegP on the way to Spec-CP or even stayed in Spec-NegP since this is also an $\mathrm{A}^{\prime}$ position. The evidence for the in situ licensing of these NPI's is that they can co-occur with sha, which can move to Spec-NegP overtly as seen in (32). Agidge 'no one' as shown in (33) can not be extracted regardless of whether sha stays in situ or precedes Neg1 ur, an extraction that is possible if sha is not present in the sentence as illustrated in (22) above.

$$
\begin{aligned}
& {\left[\begin{array}{l}
\text { NegP Sha }[\text { Neg ur } \\
\text { Neg2 }
\end{array}\right.} \\
& \text { 'No one left.' }
\end{aligned}
$$


(33)
*agidge (sha) ur iddin (sha)
No one $(*$ Neg2 $)$ Neg1 went $(*$ Neg2)

(34)
sha-ur
3lix
walu.
Neg2-Neg1 see-Pef-1s nothing
'I didn't see anything.'
walu ur 3lix
nothing neg see-Perf-1s
(*sha).
'Nothing did I see.'

This, I believe, is strong evidence for Locality conditions on NPI movement. NPI's like agidge 'no one' and walu 'nothing' in (34) and (35) cannot be extracted across any other intervening negation phrase as illustrated in the structure in (36).

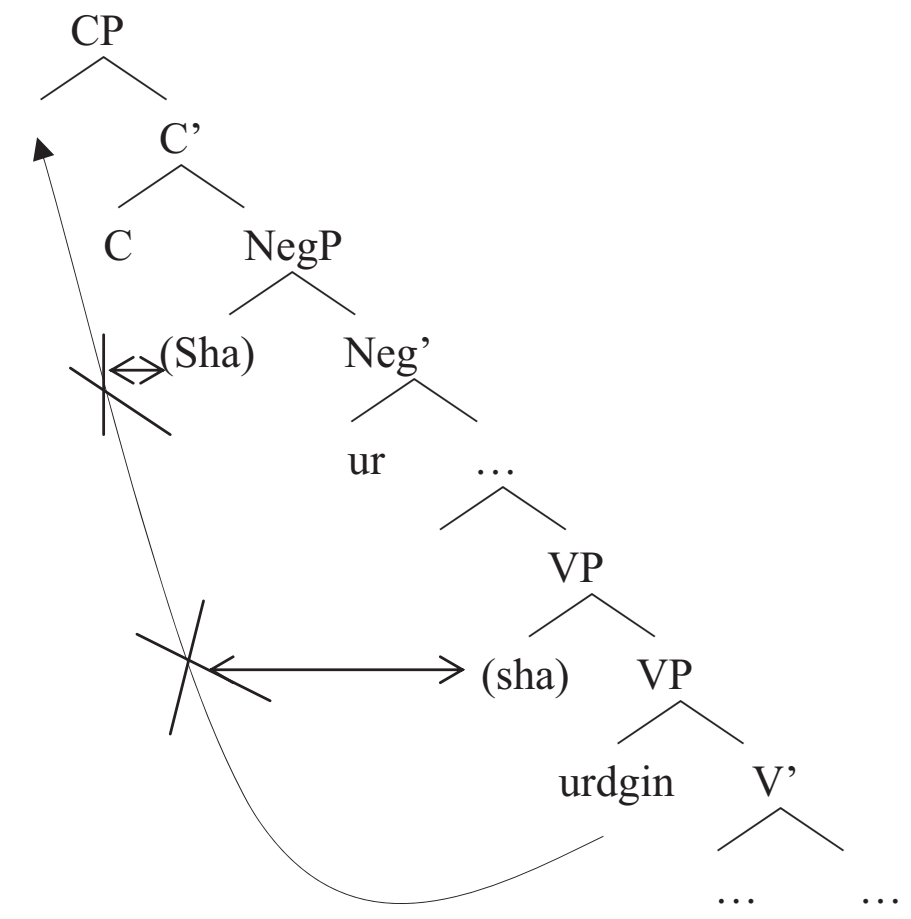

Adverbs like urdgin and ursar 'never', on the other hand, are licensed by being (externally) merged in Spec-Neg. The use of urdgin or ursar depends on whether the verb conveys past or present information. Urdgin is used only with verbs in the imperfective form as in (37) and ursar is used with verbs in the perfective form to convey the future as in (38). Sha (Neg2) cannot co-occur with these NPI adverbs as shown in these two previous examples (37-38).

$$
\begin{array}{lllll}
\text { urdgin }(* \text { sha }) & \text { ur } & \text { dix } & (* \text { sha }) & \text { gher frans. } \\
\text { never }(* \text { Neg2) } & \text { Neg1 } & \text { went-Perf-3s } & (\text { Neg2 }) & \text { to France }
\end{array}
$$

'I have never been to France.' 


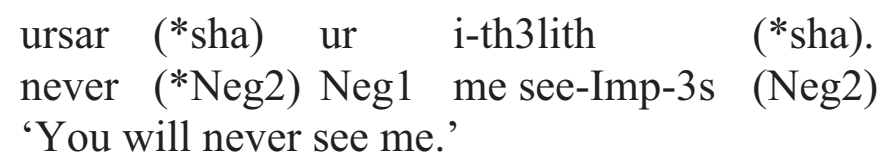

This fact follows from the assumption made above about the position these adverbs occupy, i.e., Spec-Neg. Sha can only be licensed via Spec-Head with $\mathrm{Neg}^{0}$, but if this position is occupied the licensing cannot take place and consequently the derivation crashes. This is illustrated in the structure in (39).

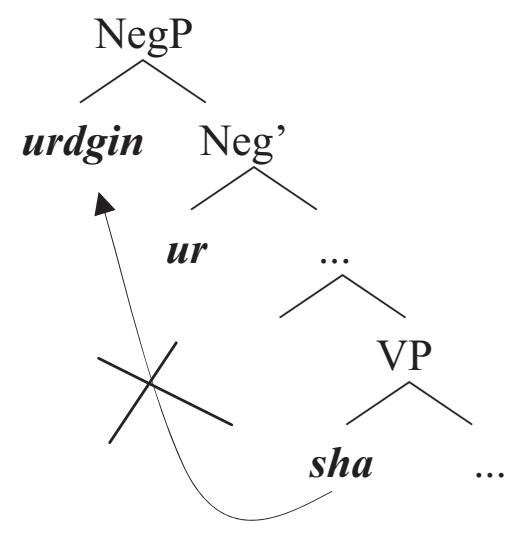

\section{Conclusion}

In this paper I have shown that there are two types of Berber dialects, those with negative concord and those that use one negation element. By discussing the interaction of Neg2 sha with NPI's, I argued that NPI's which are arguments of the verb are licensed in situ by virtue of being c-commanded by $\mathrm{Neg}^{0}$, whereas NPI adverbs like urdgin 'never' are licensed by a Spec-Head relation with $\mathrm{Neg}^{0}$, by being merged in Spec-Neg. Licensing of both types of NPI's has to respect locality conditions.

\section{References}

Benmamoun, E. 2000. The feature structure of functional categories: A comparative study of Arabic dialects. New York: Oxford University Press.

Boumalk, A. 1996. La négation en berbère marocain. In S. Chaker and D. Caubet, eds., La négation en berbère et en arab maghrébin, 35-48. Paris: L'Harmattant.

Chaker, S. 1996. Quelques remarques préliminaires sur la négation en berbère. In S. Chaker and D. Caubet, eds., La négation en berbère et en arab maghrébin, 9-22. Paris: L'Harmattant. 
Chomsky, Noam. 1989. Some notes on economy of derivation and representation. In I. Laka and A. Mahajan, eds., Functional Heads and Clause Structure. MIT Working Papers in Linguistics 10:43-74.

Chomsky, Noam. 1995. The Minimalist Program. Cambridge, MA: MIT Press.

Chomsky, Noam. 2000. Minimalist inquiries: The framework. In R. Martin, D. Michaels, and J. Uriagereka, eds., Step by Step: Essays on Minimalist Syntax in Honor of Howard Lasnik. Cambridge, MA: MIT Press.

Fassi-Fehri, A. 1993. Issues in the Structure of Arabic Clauses and Words. Dordrecht: Kluwer.

Haegeman, L., and R. Zanuttini. 1996. Negative concord in West Flemish. In A. Belletti and L. Rizzi, eds., Parameters and Functional Heads, 117-179. New York: Oxford University Press.

Holmberg, A., et al. 1993. The structure of Infl and the finite clause in Finnish. In A. Holmberg and U. Nikanne, eds., Case and Other Functional Categories in Finnish, 177-206. Berlin: Mouton de Gruyter.

Kayne, Richard. 1989. Null subjects and clitic climbing. In O. Jaeggli and K. Safir, eds., The Null Subject Parameter, 239-261. Dordrecht: Kluwer.

Lafkioui, M. 1996. La négation en tarifit. In S. Chaker and D. Caubet, eds., La négation en berbère et en arab maghrébin, 49-77. Paris: L'Harmattant.

Laka, Itziar. 1990. Negation in syntax: On the nature of functional categories and projections. Ph.D. diss., MIT.

Nait-Zerrad, K. 1994. Manuel de conjugaison Taqbaylite. Paris: L'Harmattant.

Ouali, H. 1999. The clause structure and clitics in Berber. Masters thesis, University of Tromsø.

Ouali, H. 2003a. Sentential negation in Berber: A comparative study. In J. Mugany, ed., Linguistic Description: Typology and Representation of African Languages. Trends in African linguistics, vol. 8. Trenton, NJ: Africa World Press.

Ouali, H. 2003b. Object pronominal clitic placement and generalized V2 in Tamazight Berber. Ms., University of Michigan.

Ouhalla, Jamal. 1988. The syntax of head movement: A study of Berber. Ph.D. diss., University College London.

Ouhalla, Jamal. 1989. Clitic movement and the ECP: Evidence from Berber and Romance languages. Lingua 79:165-215.

Ouhalla, J. 1990. Sentential negation, relativized minimality and the aspectual status of auxiliaries. The Linguistic Review 7:183-231.

Ouhalla, Jamal. 1991. Functional Categories and Parametric Variation. London and New York: Routledge.

Ouhalla, Jamal. 1993. Subject-extraction, negation and the anti-agreement effect. Natural Language \& Linguistic Theory 11:477-518.

Ouhalla, Jamal. 2005. Clitic placement, grammaticalization, and reanalysis in Berber. In G. Cinque and R. Kayne, eds., The Oxford Handbook of Comparative Syntax. Oxford and New York: Oxford University Press. 


\section{Hamid Ouali}

Pollock, J.-Y. 1989. Verb movement, universal grammar and the structure of IP. Linguistic Inquiry 20:365-424.

Rabhi, A. 1996. De la négation en berbère: les données algériennes. In S. Chaker and D. Caubet, eds., La négation en berbère et en arab maghrébin, 23-34. Paris: L'Harmattant.

Zanuttini, R. 1994. Re-examining negative clauses. In G. Cinque, J. Koster, J.-Y. Pollock, L. Rizzi, and R. Zanuttini, eds., Paths towards Universal Grammar: Essays in Honor of Richard S. Kayne. Washington, DC: Georgetown University Press.

4080 Frieze BL

105 South State Street

Ann Arbor, MI 48109-1285

houali@umich.edu 